\title{
Use of Cotton Straw during Composting To Bringdown the Cost of Mushroom Production
}

\author{
Dr. Parveen Garg \\ Department of Botany, Swami Shradhanand College, University of Delhi, Alipur, Delhi- 110036
}

\begin{abstract}
Considering the high cost of wheat straw in local market, three different combinations wheat and cotton straw were tested for their influence on yield and cost of production of Button Mushroom. Agaricus bisporous (lange) Sing. Compost was prepared by mixing 10\%, 20\% and 30\% Cotton and wheat straw by long method of composting. 100\% wheat straw was used as control. All the ingredients composted for 20 days single phase out door composting as advocate by Kapoor ${ }^{l .}$ Fresh grain spawn was obtained from Bharat Mushrooms, Delhi. Formaldehyde treated casing soil (1:1 mixture of 2year old farm yard manure and garden soil) was used for casing of beds. The results show that all the combinations affected yield and proved to be promising for low cost production of mushroom. Combination with $30 \%$ Cotton straw and $70 \%$ wheat straw gave maximum production of mushroom $\left(8.4 \mathrm{Kg} / \mathrm{m}^{2}\right)$.
\end{abstract}

Subject: Basic science

Keywords: Cotton Straw, Compost, Agaricus bispsorus, button mushroom

\section{Introduction}

Mushroom compost is a highly complex substrate offering appropriate nutrition to the mushroom mycelium while discouraging growth of other microorganisms. The compositing technique used to prepare this complex substrate is not only complicated but difficult to examine due to usage of large number of different types of raw materials used for its preparation. A great deal of research into compost ingredients, as well as composting process has led to better understanding of the process itself. Compost plays a comprehensive and important role in mushroom production than doe's soil in higher plants. This material is the result of decomposition process governed by a number of micro-organisms that produce important chemical and biological reactions thereby making it selective for Aaricus Bisporus. Due to non availability of horse manure compost, formulation based on wheat straw plus other nutrients (organic and inorganic) has become the standard and is being used by all the commercial mushroom units in India. Various formulations have been developed by different workers from time to time which are mainly based on locally available materials $\left(\right.$ Schister $^{2}$; Shandilya ${ }^{3,4}$; Hayes and Shandilya ${ }^{5}$; Dhar et.all ${ }^{6}$ ). Due to constant striving for higher returns in mushroom cultivation, it is desirable to bring down the cost of raw materials thus compost production using cotton straw which is available almost free of cost everywhere in India was paid attention to and tested for its capability to produce quality compost initially in combination with traditionally used wheat straw which is very expensive and beyond the reach of normal farmers. The present investigation deals with the mixing of easily available, cheap cotton straw to wheat straw during composting and to test this combination for its availability to affect yield and cost of mushroom production.

\section{Materials and methods}

Wheat straw, Cotton straw and chicken manure were procured locally. Fresh grain spawn of Agaricus bisporus (lange) sing, strain S 11was obtained from Bharat Mushrooms, Delhi, India. Formaldehyde treated casing soil (1:1 mixture of 2 year old farm yard manure and garden soil) was used for casing of beds.

Straw based compost with different combinations of wheat and cotton straw was prepared by long method. All the ingredients (Table-1) were composted for 20 days of single phase composting as advocated by Kapoor ${ }^{1}$. Pre wetting for 2-3 days was followed by 18 days of outdoor composting on concrete floor.

Supplements like chicken manure, wheat bran, urea (Table-1) were sprinkled over it on first day of stacking ( $3^{\text {rd }}$ day of composting). Gypsum was added on $14^{\text {th }}$ day. Initial nitrogen content of the compost pile was kept $1.70-1.75 \%$.

Spawn was mixed with the compost of $0.6 \%$ by thorough spawning method in all the sixteen trays $(1.0$ $\mathrm{m}^{2}$ ) each containing $60 \mathrm{~kg}$ of compost $(72 \%$ moisture) spawned trays were covered with polythene sheets. After spawn run polythene sheets were removed and the trays were cased with formaldehyde (41\%) treated casing soil to a thickness of $4.0 \mathrm{~cm}$. Regular watering and appropriate ventilation specially at the time of pinhead formation was provided in growing room. Mushrooms were picked for 60 days and the weight of mushrooms recorded daily for each tray to determine yield. Yield was determined as kilogram per square meter. The yield response 
indicated that compost mixture with $30 \%$ cotton straw and $70 \%$ wheat straw gave maximum production of mushroom $\left(8.4 \mathrm{~kg} / \mathrm{m}^{2}\right)$.

\section{Results and Discussion}

Total nitrogen content of all the compost was same during stacking. The yield data of four $\left(\mathrm{C}_{1}-\mathrm{C}_{4}\right)$ compost mixtures (Table-2) showed that composts with cotton straw meal were statistically at par with maximum productivity at $30 \%$ mixture of cotton straw. Yield beyond two months was not recorded, it is probable that all grades of composts had given more yield even beyond the period recorded.

The changes in normal cultivation practices studied in this experiment were found to be significant not only as alternative to pure wheat straw but also on account of economic considerations. Most significant effect of the new combination is the emergence of new alternative to wheat straw. Not only Cotton straw which proved its efficiency during the experiments, but other kind of straws like mustard, paddy, arhar can also be considered for straw based compost preparation.

Table 1: Composition of Composts

\begin{tabular}{|lllll|}
\hline Ingredients Kg & $\mathbf{C - 1}$ & $\mathbf{C - 2}$ & $\mathbf{C - 3}$ & $\mathbf{C - 4}$ \\
\hline Wheat Straw & 300 & 270 & 240 & 210 \\
Cotton Straw & - & 30 & 60 & 90 \\
Chicken manure & 80 & 80 & 80 & 80 \\
Urea & 3 & 3 & 3 & 3 \\
Wheat Bran & 25 & 25 & 25 & 25 \\
Nuvon (ml) & 30 & 30 & 30 & 30 \\
\hline
\end{tabular}

Table 2: 60 days yield ${ }^{*}(\mathrm{Kg})$ from composts

\begin{tabular}{|lllll|}
\hline Compost & Yield $/ \mathrm{m}^{2}$ (a) 1 month & Yield $/ \mathrm{m}^{2}(\mathrm{~b}) 2$ month & Yield $/ \mathrm{m}^{2}(\mathrm{a}+\mathrm{b})$ & Yield $/ \mathrm{mT}$ of Compost \\
\hline C-1 & 3.8 & 3.4 & 7.2 & 120 \\
C-2 & 4.6 & 3.6 & 8.2 & 137 \\
C-3 & 5.2 & 3.8 & 9.0 & 145 \\
C-4 & 5.2 & 3.2 & 8.4 & 140 \\
\hline
\end{tabular}

* Mean of four trials.

\section{References}

[1]. Kapoor JN (1989) In Mushroom cultivation (Publication and Information Division. ICAR, New Delhi), 28.

[2]. Schisler LC (1964) MGA Bull 179; 503.

[3]. Shandilya TR (1976) Ind J Mush 2; 43.

[4]. Shandilya TR (1980) Taiwan Mush 4; 6.

[5]. Hayes WA and shandilya TR (1977) Ind J Mycol \& plant PAthol 7; 5.

[6]. Dhar BL, Vijay B, Upadhyaya RC and Sohi HS (1985) Ind J Mycol \& Plant Pathol 15. 